\title{
NORMAS INTERNACIONAIS DE PRESERVAÇÃO DO PATRIMÔNIO HISTÓRICO E CULTURAL (1931 - 2003)
}

Ian Ferreira

Universidade Federal do Amazonas ian_apj@hotmail.com

Adriano Ferreira

Universidade Federal do Amazonas adrianoferreira@ufam.edu.br

Ana Luíza do Rosário Universidade Federal do Amazonas rosario.analuizaas@gmail.com

\section{RESUMO}

A partir de uma revisão bibliográfica, as reflexões propõem demonstrar de que forma a preservação do patrimônio histórico e cultural se perfaz como garantia de que os povos se mantenham como integrantes participativos da narrativa histórica. Para tanto, o debate parte de reflexões conceituais e de que forma a cultura e suas manifestações interferem no processo de construção da individualidade e da identidade social, culminando no estudo dos mecanismos internacionais e internos de preservação ao patrimônio histórico e cultural material e imaterial e na importância de sua observação para além da generalização e homogeneização das manifestações culturais.

Palavras-chave: Normas internacionais. Preservação. Patrimônio histórico e cultural.

\section{NORMAS INTERNACIONALES DE PRESERVACIÓN DEL PATRIMONIO HISTÓRICO Y CULTURAL (1931 - 2003)}

\section{RESUMEN}

A partir de una revisión bibliográfica, las reflexiones proponen demostrar de qué forma la preservación del patrimonio histórico y cultural es una garantía de que los pueblos se mantengan como integrantes de la narrativa histórica. Para estos fines, el debate parte de reflexiones conceptuales y de qué forma la cultura y sus manifestaciones interfieren en el proceso de construcción de la individualidad e de la identidad social, culminando en el estudio de los mecanismos internacionales e internos de preservación del patrimonio histórico y cultural material e inmaterial y en la importancia de suya observación para allá de la generalización y homogeneización de las manifestaciones culturales.

Palabras-clave: Normas internacionales. Preservación. Patrimonio histórico y cultural.

\section{INTERNATIONAL STANDARDS ON THE PRESERVATION OF THE HISTORICAL AND CULTURAL HERITAGE (1931 - 2003)}

\section{ABSTRACT}


From a bibliographic review, the considerations aim to demonstrate how the preservation of the historical and cultural heritage works to guarantee that the peoples themselves integrate the historical narrative. To do so, the debate starts with conceptual considerations and how the culture and its manifestations interfere in the process of building the individuality and social identity, leading to the study of international and internal mechanisms of preservation of the historical and cultural material and immaterial heritage and the importance of its observation beyond generalizations and homogenization of the cultural manifestations.

Keywords: International law. Preservation. Historical and cultural heritage.

\section{NORMES INTERNATIONALES DE PRESERVATION DU PATRIMOINE HISTORIQUE ET CULTUREL (1931 - 2003)}

\section{RÉSUMÉ}

Dans de une révision bibliographique, les réflexions proposent de démontrer comme la préservation du patrimoine historique et culturel est aussi une assurance aux peuples d'être intégrantes participatifs de la narratif historique. À cet effet, le débat s'agit des réflexions conceptuelles et sur l'interférence qui ont la culture et ses manifestations dans les procédé de la construction de l'individualité e de l'identité sociale, finissant avec l'étude des mécanismes internationaux et internes de préservation du patrimoine historique et culturel matérielle et immatérielle et l'importance de son respect au-delà de la généralisation et homogénéisation de las manifestations culturelles.

Mots-clés: Droit internacional. Préservation. Patrimoine historique et culturel.

\section{INTRODUÇÃO}

Nos últimos 3 anos testemunhamos situações que colocaram em cheque a preservação histórico-patrimonial em algumas regiões do globo. Qualquer pessoa que tenha acesso a meios de comunicação pôde acompanhar praticamente em tempo real o incêndio na Catedral de Nôtre Dame de Paris em 15 de abril de 2019 e a posterior mobilização mundial em prol da reconstrução da igreja. Tanta foi a repercussão que a notícia virou o principal tópico debatido em jornais e foi headlineem diversos países. Devido a essa repercussão, pensamos: o que leva a sociedade a ser tão afetada pela destruição de um prédio construído há mais de 800 anos? Indo além: o que leva essa mesma sociedade a se mobilizar pela reconstrução doando valores na casa dos bilhões?

Não precisamos atravessar o Atlântico para ter outro exemplo como esse. Em setembro de 2018 o Museu Nacional do Brasil também foi consumido pelas chamas e um patrimônio histórico incomensurável foi perdido naquele dia. Peças como Luzia, registros gráficos da linguagem de povos indígenas, artefatos arqueológicos e biológicos estavam em 
situação de risco e muitos deles foram perdidos. Esse mesmo fato também nos leva a refletir sobre a necessidade de se manter o bom estado de conservação desses materiais a fim de que possam cumprir o seu papel, que é o de produzir ciência e de reproduzir as culturas neles preservadas.

Sendo assim, a discussão trazida pela presente reflexão visa se aprofundar na necessidade da preservação do patrimônio histórico e cultural e de que forma a comunidade internacional vem se empenhando para a concretização dessa tarefa. O conhecimento desta matéria vai se desdobrando e permeando as questões específicas levantadas durante o presente e aumenta a perspectiva crítica da forma de pensar o Direito, fazendo com que se tenha um ponto de vista mais geral e sobre questões específicas, concluindo-se que, mesmo diante de fatos concretos é necessário ser estudado o conceito do que é "cultura" e o que é "patrimônio", evitando generalizações.

A partir dessas considerações, será iniciada a exposição da hereditariedade da expressão cultural, por meio da sociologia e da antropologia, através da cronologia na humanidade abordando-se, ao fim dessas reflexões, o contexto em que surgiu a preocupação normativa com a preservação do patrimônio histórico e cultural. Para tanto, faz-se necessário conceituar o patrimônio material e imaterial bem como apresentar discussões históricas e interdisciplinares junto a matérias que tangenciam a temática em tela para que em seguida se inicie a discussão jurídica com o estudo dos mecanismos internacionais e internos de proteção ao patrimônio histórico e cultural, analisando a relevância social desta preservação.

A fim de delinear a cronologia dos dispositivos legais, foram separadas as Cartas e Convenções Patrimoniais de momentos específicos da história global, sendo elas as Cartas de Atenas de 1931 e 1933, antes da Segunda Guerra Mundial e todas as demais após a Segunda Guerra Mundial, as quais evoluíram gradativamente no aspecto garantidor, com destaque para as cartas latino-americanas da década de 1990 que trouxeram inovações para a proteção da diversidade e da expressão cultura dos povos nativos.

\section{CULTURA, PATRIMÔNIO E SUA PROTEÇÃO}

\section{O conceito de cultura}

Primeiramente, o ponto de partida para as discussões deve ser a questão conceitual acerca do que seria "cultura", isso se deve porque, como será abordada a proteção normativa 
ao patrimônio cultural, primeiro é necessário se definir o que será protegido para então haver aptidão para protegê-lo, de fato.

Ainda que seja meramente conceitual essa discussão, entende-se que o que se é entendido por "cultura" não é aplicado de forma homogênea entre os povos, visto que não é um imperativo categórico (SILVA, 2007, p. 4), sobretudo por ser um conceito que deriva de vivências e da realidade vivida.

Conforme os pensamentos do sociólogo Émile Durkheim, a cultura seria o processo de subsunção dos valores genéricos por meio dos indivíduos, a fim de que, através dessa subsunção, fosse estabelecida a ordem social por meio de uma uniformidade de ações dos elementos da sociedade (PORTO, 2011). Para Weber, a cultura teria um significado e "dinâmica" parecida, visto que para ele cultura também seria o resultado das diversas relações que os indivíduos da sociedade criam entre si (WEBER, 1982), dando à cultura uma conotação mais pragmática com base nas vivências sociais.

Portanto, tomando como base quiçá os dois maiores e precursores nomes da Sociologia, percebe-se que é inviável que seja estabelecido um conceito universalizante do que é "cultura", sobretudo quando partimos do pressuposto de que ela se origina das vivências de cada sociedade dentro de sua especificidade. Dessa forma, já que cada sociedade tem uma vivência diferente da outra, então a vivência específica de cada uma dessas sociedades gerará suas respectivas "culturas" que serão expressadas e externalizadas das mais variadas formas, seja pela música, pelo teatro, escultura, literatura, dança e etc.

Não obstante, ainda há outras áreas dentre as Ciências Humanas que estudam o que seria cultura. Antropologicamente, conforme os estudos de Alessandro Duranti, a cultura teria mais de uma dimensão e possibilidade de definição (DURANTI, 1997), que poderiam ser determinadas seja pela transmissão de conhecimentos, tradições e vivências de uma geração pra outra, ou pelo compartilhamento entre conhecimentos entre os membros de uma mesma sociedade, seja pela forma como a sociedade compreende o mundo ao seu redor ou como interage dentro desse meio.

Representando os pensadores brasileiros, o antropólogo Roque Laraia (2001) concentra todas essas correntes de pensamento em seu conceito próprio, concluindo que uma dimensão dessa não exclui a outra, de forma que o indivíduo, ao mesmo tempo em que recebe informações culturais de seus antepassados, também pode construir sua própria vivência a partir das experiências que tem no meio em que está inserido. 
Após passar por séculos de ressignificação, conforme os estudos e reflexões de Jhon B. Thompson (2009), desde a Expansão Marítima europeia atravessando a Revolução Francesa e as imposições dos países europeus no contexto do neoimperialismo do fim do século XIX, o termo "cultura" chega à modernidade com uma perspectiva necessariamente diferenciada, visto que agora não é mais cabível subsistirem modelos sociais que tentem sobrepor sua cultura à de outras sociedades.

Dessa forma, é possível compreender que para que haja uma definição do que é "cultura" não é suficiente apenas um ramo da ciência, de forma que o Direito e as Ciências Jurídicas necessitam da interdisciplinaridade para que alcancem um significado que contemple as sociedades de uma forma mais abrangente (CANEDO, 2009), sobretudo quando se é analisado o alcance internacional das normas de proteção ao patrimônio e à cultura.

Em sendo um fator que define intrinsecamente a posição e o papel do indivíduo dentro e a partir do meio social, bem como o instrumento por meio do qual o indivíduo acessa as vivências ancestrais e propaga as presentes, percebe-se que a "cultura" está presente em grande parte (senão em todos) os espaços ocupados pelo indivíduo. Dada a sua importância, não seria plausível que as Ciências Jurídicas excluíssem de sua alçada tal proteção, que indiscutivelmente é um bem jurídico tutelável que merece atenção e, a fim de não sobrepor as vivências de uma sociedade em detrimento da outra, o estudo interdisciplinar e a análise conceitual da abrangência do termo "cultura" é essencial para que as normas tenham sua atuação delimitada de forma eficaz.

\section{2. $O$ conceito de patrimônio}

Partindo da reflexão das determinações internacionais, com base na Convenção para a Proteção do Patrimônio Mundial, Cultural e Natural (1972), a mesma traz em seu artigo $1^{\circ}$ a seguinte redação:

ARTIGO 1. Para os fins da presente Convenção, são considerados "patrimônio cultural": - os monumentos: obras arquitetônicas, esculturas ou pinturas monumentais, objetos ou estruturas arqueológicas, inscrições, grutas e conjuntos de valor universal excepcional do ponto de vista da história, da arte ou da ciência; - os conjuntos: grupos de construções isoladas ou reunidas, que, por sua arquitetura, unidade ou integração à paisagem, têm valor universal excepcional do ponto de vista da história, da arte ou da ciência $[\ldots]$. 
Trazendo a discussão para o âmbito interno brasileiro, a Constituição Federal (1988) delimita:

$\mathrm{CF} / 88$. Art. 216. Constituem patrimônio cultural brasileiro os bens de natureza material e imaterial, tomados individualmente ou em conjunto, portadores de referência à identidade, à ação, à memória dos diferentes grupos formadores da sociedade brasileira, nos quais se incluem: I - as formas de expressão; II - os modos de criar, fazer e viver; III - as criações científicas, artísticas e tecnológicas; IV - as obras, objetos, documentos, edificações e demais espaços destinados às manifestações artístico-culturais; $\mathrm{V}$ - os conjuntos urbanos e sítios de valor histórico, paisagístico, artístico, arqueológico, paleontológico, ecológico e científico.

Com isso, percebe-se que o conceito de "patrimônio" abrange não somente objetos materialmente tangíveis, mas também formas de expressão da sociedade e os seus costumes. Nas palavras de LOPIS (2017, p. 11) "o elemento patrimonial cultural deve estar atrelado ao seu contexto de um passado histórico e social, não como um artefato isolado", de forma que:

faz-se necessário perceber que o patrimônio não é só um bem em si, mas também o uso que aquele bem tem para a perpetuação da memória de uma coletividade, pois o patrimônio histórico não é algo concreto somente, é algo também subjetivo, cheio de significado. (LOPIS, 2017, p. 12).

Dito isso, percebe-se que a carga significativa da qual é dotada o patrimônio vai muito além de um elemento pontual, mas sim carrega o processo de identificação de uma determinada sociedade e elementos de compreensão de vivências passadas. Em consonância com esse entendimento, podemos, então, concluir que:

a definição de Patrimônio, portanto, vai além das duas classificações como patrimônio material e imaterial, segundo o faz a Unesco, em termos mundiais, e o Instituto do Patrimônio Histórico e Artístico Nacional (Iphan), no Brasil. (MELO; CARDOZO, 2015, p. 1062).

E, que "trabalhar com o patrimônio na perspectiva aqui delineada significa levar em conta as relações reais levadas a efeito por homens reais em situações históricas concretas" (MELO; CARDOZO, 2015, p. 1063).

Portanto, não seria abrangente o suficiente limitar "patrimônio" apenas por meio de significações materiais e enquadrá-lo apenas como construções, edifício e afins. Essa reflexão se faz necessária visto que, quando tratamos de normas internacionais de proteção ao patrimônio, devem ser observados os processos de identidade e de construção da identidade 
conforme as especificidades de cada nação, atentando-se a heterogeneidade dos povos, que são transmitidas para além do patrimônio material, estando contidas, também, no patrimônio imaterial.

\title{
3. Evolução Histórica da Problemática
}

Fazendo um recorte mais contemporâneo acerca das discussões apresentadas, percebemos que desde a Revolução Francesa as questões sociais passaram a ocupar as pautas estatais, sobretudo por esse marco histórico representar a ruptura com o modelo de regime arcaico e segregacionista.

No século seguinte, com o advento das inovações da Revolução Industrial, as questões sociais ganharam uma nova dimensão de discussão, visto que passaram a estar intrínseca e visivelmente atreladas às questões econômicas. A partir disso, análise dos impactos dos modelos industriais das nações passou a ser discutida por diversos teóricos.

Nesse ínterim, nas décadas de 1860 e 1870 surgiram os movimentos nacionalistas e de integração na Europa central, o que favorecia o entendimento do fortalecimento do poder do Estado por meio da união e de um povo só, o que seria possível através do resgate e da conservação dos modelos culturais que geravam esse vínculo entre os indivíduos.

\begin{abstract}
A tutela internacional do patrimônio cultural relaciona-se com a necessidade de manter-se a integridade física desses bens, apresentando, em forma de tratados internacionais protetores dos bens culturais em hipótese de conflito armado, a exemplo da Convenção de Haia de 1899 e 1907 que estabelece a obrigação de os Estados beligerantes respeitarem os monumentos históricos o quanto possível. (MOURA, 2012, p. 93).
\end{abstract}

A partir disso, entende-se que, mesmo em meio no cenário europeu instável anterior à Primeira Guerra, era resguardado o ideal de preservação dos elementos que geravam a união identitária das nações. Passado esse período, nas décadas de 1920 e 1930, na França, as fontes do que outrora compunham o conceito de "patrimônio" foram aumentadas.

O que mais caracteriza esta perspectiva histórica é que ela adota, como meios para contar a História, materiais, falas, documentos, personagens etc., que sempre foram discriminados pela historiografia oficial. Passa-se, por exemplo, a valorizar a história do cotidiano, das classes subalternas, das organizações clandestinas, dos estudos de caso, o estudo da História dos valores, crenças entre outros temas. (MELO; CARDOZO, 2015, p. 1067). 
Aqui, se tem uma visão mais próxima do que é a atual, visto que as noções de preservação se estendem para além do que é material e edificado, alcançando também as vivências e costumes, de forma que essa ideia foi reforçada após os impactos que a Segunda Guerra trouxe, oportunidade na qual "veio a preocupação em salvaguardar bens culturais e identitários, pois estes eram sinônimo de vínculo social, de uma herança deixada por seu povo, contribuindo para a construção de uma identidade nacional" (LOPIS, 2017, p. 13).

Foi a partir da concepção da Organização das Nações Unidas que foram mais visivelmente delineados os ideais que guiariam a humanidade em busca de uma sociedade menos segregacionista, pois foi somente após o testemunho das consequências do holocausto que a comunidade internacional percebeu a necessidade de se serem positivados as garantias humanas, ainda que básicas e, junto delas, estavam as de proteção ao patrimônio histórico e cultural.

No entanto, foi a partir da Segunda Grande Guerra que novos valores foram sendo incorporados à questão ambiental, reclamando tutela nacional e internacional. Assim, várias normas jurídicas direcionadas à preservação dos bens culturais foram editadas. (MOURA, 2012, p. 92).

É nesse contexto que surge a reunião que deu origem ao marco inicial para a positivação das normas internacionais de proteção ao patrimônio histórico e cultural, próximo objeto do estudo.

\section{Contexto Histórico da Convenção para a Proteção do Patrimônio Mundial, Cultural e Natural e o empenho da comunidade internacional}

Acompanhando o contexto histórico da ressignificação do que era cultura, da importância da sua preservação bem como da preservação de sua forma de expressão, chegamos ao contexto da reunião realizada em 1972, em Paris, cujo cerne foi o debate acerca da proteção ao patrimônio cultural das nações.

Após testemunhar a devastação do continente europeu devido às duas Grandes Guerras, os países sentiram a necessidade de consignar diretrizes que norteariam as ações das nações em prol da proteção de seu patrimônio cultural, e, em face do avanço econômico da indústria, nessa convenção também foram inseridas discussões acerca da preservação do patrimônio natural também. 
No preâmbulo da Convenção para a Proteção do Patrimônio Mundial, Cultural e Natural, lemos:

Constatando que o patrimônio cultural e o patrimônio natural se encontram cada vez mais ameaçados de destruição não somente devido a causas naturais de degradação, mas também ao desenvolvimento social e econômico agravado por fenômenos de alteração ou de destruição ainda mais preocupantes.

Essa consideração nos permite concluir que o contexto de idealização da convenção era majoritariamente o contexto de expansão das economias industriais do século XX e o avanço do capitalismo ocidental em meio aos momentos de maior tensão da Guerra Fria, o que ensejava, certamente, na desconsideração da necessidade de proteção dos bens culturais em detrimento do avanço desenvolvimentista.

A partir de então, foram instituídas diretrizes de atuação e de catalogação dos bens tutelados pela mesma Convenção, como em seu Artigo $4^{\circ}$ "Cada Estado-parte da presente Convenção reconhece que lhe compete identificar, proteger, conservar, valorizar e transmitir às gerações futuras o patrimônio cultural e natural situado em seu território" e:

ARTIGO 8. 1. Fica instituído, junto à Organização das Nações Unidas para a Educação, a Ciência e a Cultura, o Comitê Intergovernamental de Proteção do Patrimônio Mundial Cultural e Natural de Valor Universal Excepcional denominado "Comitê do Patrimônio Mundial".

Deste então, o esforço internacional se direciona a esses objetivos a partir do reconhecimento da importância da preservação do patrimônio cultural e da transmissão de seu entendimento para as gerações posteriores. Fato este pode ser evidenciado através das ações de blocos econômicos como o Mercosul $^{1}$ e até mesmo, mais recentemente, quando a UNESCO inseriu a discussão em meio à realidade global durante a pandemia do novo coronavírus $^{2}$.

\section{Por que é importante se preservar o patrimônio e a cultura dos povos?}

\footnotetext{
1 Mais discussões acerca dessas políticas podem ser encontradas em: Patrimônio Cultural do Mercosul, IPHAN. Disponível em: http://portal.iphan.gov.br/pagina/detalhes/411.Acesso em 10 de junho de 2020. ${ }^{2}$ Notícia completa disponível em: UNESCO lança iniciativas para apoiar cultura e patrimônio durante a pandemia, 2020. Disponível em: https://nacoesunidas.org/unesco-lanca-iniciativas-para-apoiar-cultura-epatrimonio-durante-a-pandemia/. Acesso em 10 de junho de 2020.
} 
Como ponto inicial das reflexões do presente, foi feita análise interdisciplinar do conceito de "cultura" e de "patrimônio histórico". Dessa forma, remetendo-se ao que já foi exposto na parte conceitual, faz-se necessário refletir o porquê da necessidade de haver mobilização internacional por meio de uma legislação que promova e contemple a proteção do patrimônio e da cultura dos povos.

As reflexões conceituais sobre "cultura" levaram à compreensão de que esta é um elemento intrínseco às vivências do indivíduo e do qual ele, inserido no meio social, não pode se eximir. Conforme de Godoy e Santos (2014, p. 32):

[a] subjetividade, inspirada por um contexto social, marcadamente linguístico e cultural, influencia a construção de nossa identidade, ou seja, é o social, o linguístico e o cultural atuando, direta ou indiretamente, em quem somos e como pensamos e agimos.

Para "subjetividade", os supracitados autores usam o conceito de Kathryn Woodward (2009), para quem:

a subjetividade indica a compreensão de si mesmo, pois reúne os pensamentos e as emoções tanto conscientes quanto inconscientes que definem as concepções, certezas e incertezas que construímos sobre nós mesmos. (GODOY; SANTOS, 2014, p. 32).

Com essas reflexões, conclui-se que indubitavelmente o elemento cultural merece atenção do Direito por ser parte integrante do indivíduo, assim como a vida e a liberdade, asseguradas a todos indistintamente, afinal, seria contraditório assegurar o indivíduo o direito à vida e o direito a se expressar da maneira que bem entender e ao mesmo tempo negar-lhe as vivências sociais e antropológicas que o fazem compreender seu local e sua função dentro do meio social, bem como não seria cabível lhe assegurar os demais direitos fundamentais sem que fosse garantida também a oportunidade de transmitir suas vivências para as gerações futuras e receber tais vivências das gerações passadas.

O que se põe em questão é que assim como as demais garantias, que no Brasil se encontram na Constituição Federal (1988), a cultura também é parte essencialmente integrante do indivíduo e não pode ser afastada do elemento jurisdicional dos Estados, sob pena de tornar a experiência humana incompleta. Complementando essas reflexões, Alfredo Veiga Neto (2003) expõe que a "cultura" tem ganhado cada vez mais espaço dentre as discussões, visto que é elemento essencial para a compreensão da contemporaneidade. 
Adiante, como parte integrante da expressão cultural, tem-se o "patrimônio", nos termos do que já foi apresentado. Compondo o rol de exemplos de ocorrências em que o patrimônio histórico da humanidade foi afetado, temos as diversas ocorrências de depredação cometidas pelo Estado Islâmico ${ }^{3}$. Em resposta aos ataques terroristas que destruíram parte dos registros históricos da região, o Conselho de Segurança da Organização das Nações Unidas editou a Resolução n 2347, de 2017, em cujo preâmbulo consta:

Acolhendo o papel central da UNESCO em proteger o patrimônio cultural e promover a cultura como instrumento de aproximação entre as pessoas e alimentando o diálogo, incluindo a campanha \#Unite4Heritage... ${ }^{4}$ (tradução livre dos autores).

E "Notando os já existentes esforços do Comitê do Conselho Europeu sobre Ofensas a Bens Culturais acerca do panorama legal de combate ao tráfico ilícito de bens culturais...” (tradução livre dos autores) ${ }^{5}$.

A partir desses excertos, percebe-se a preocupação dos organismos internacionais com a proteção do patrimônio histórico, visto que estes carregam a herança cultural das nações em questão. Dessa forma, a dissociação entre "cultura" e "patrimônio" é impossível, dado que este é nada mais do que a expressão visual e material daquela. Portanto, uma vez que se assegura a proteção do patrimônio, se assegura também proteção de parte da cultura e da manifestação cultural, concluindo-se que as garantais em favor de um são tão importantes quanto as garantias em favor do outro.

Por fim, corroborando essas considerações, podemos concluir que "preservar a memória cultural de uma sociedade não significa atrelá-la ao passado e impedir o seu desenvolvimento, mas sim conservar seus pilares constituintes a fim de não perder conhecimentos e identidades" (LEMOS JÚNIOR, 2012, p. 53), preservação esta que pode ser

\footnotetext{
${ }^{3}$ Mais informações e exemplos acerca da temática podem ser encontradas em: ONU condena destruição de patrimônio cultural em Palmira pelo Estado Islâmico. Nações Unidas Brasil, 2017. Disponível em: https://nacoesunidas.org/onu-condena-destruicao-de-patrimonio-cultural-em-palmira-pelo-estado-islamico/. Acesso em 9 de junho de 2020 e ALENCAR, Lucas. 13 locais históricos destruídos pelo Estado Islâmico. Revista Galileu, 2016. Disponível em: https://revistagalileu.globo.com/Sociedade/noticia/2016/01/13-locaishistoricos-destruidos-pelo-estado-islamico.html. Acesso em 9 de junho de 2020.

4 CONSELHO DE SEGURANÇA DA ONU (CS). Resolução 2347/2017. Do original: Do original: "Welcoming the central role played by UNESCO in protecting cultural heritage and promoting culture as an instrument to bring people closer together and foster dialogue, including through the \#Unite4Heritage campaign..." Disponível em: https://www.un.org/press/en/2017/sc12764.doc.htm. Acesso em 9 de junho de 2020.

${ }^{5}$ Ibidem. "Noting the ongoing efforts of the Council of Europe Committee on Offences relating to Cultural Property concerning a legal framework to address illicit trafficking in cultural property..."
}

Rev. Iberoam. Patrim. Histórico-Educativo, Campinas (SP), v. 6, p. 1-28, e020027, 2020. 
assegurada por meio de normatizações responsáveis e que atendam às especificidades dos povos.

\section{Convenções e Cartas Internacionais sobre a Preservação de Patrimônio Histórico e Cultural}

Como dito anteriormente, as organizações internacionais sofreram grandes impactos após os períodos de Primeira e Segunda Guerras Mundiais, o que resultou em um desejo de proteção dos patrimônios históricos ao redor do globo, simultaneamente preservando a herança cultural das nações em questão. Por esta razão, firmaram compromissos, documentos que contêm conceitos, medidas de ações administrativas e métodos para a conservação e restauração de patrimônios: as Cartas Internacionais, também chamadas de Cartas Patrimoniais, e as Convenções, todas atualizadas para continuarem com a mesma eficácia nos dias de hoje.

Para tanto, faz-se uma abordagem cronológica dos dispositivos que promovem a proteção do patrimônio histórico e cultura, analisando-se as inovações trazidas ao passar dos anos e as nuances nas abordagens jurídicas a nível internacional (nos anos de 1931, 1933, 1972, 1989 e 2003), regional (1997 e 1999) e posteriormente no cenário interno brasileiro (1970 e 1997).

\subsection{Cartas de Atenas}

A primeira carta patrimonial a ser registrada foi a Carta de Atenas, no ano de 1931, no Escritório Internacional dos Museus Sociedade das Nações e é dividida em duas partes: disposições gerais e deliberação da conferência sobre a anastilose dos monumentos da acrópole, esta servindo para votação quanto aos princípios dispostos naquela. Nas suas disposições gerais, os Estados-membro concordaram que a diferença entre as legislações distintas resultam em dificuldades de conciliar o direito público e o particular. Isto exposto, a decisão quanto ao interesse integral, cuja esperança da dita conferência é que sejam as leis adaptadas às circunstâncias locais e à opinião pública, é que a autoridade pública de cada Estado seja investida de poder para a tomada de medidas de conservação em casos de urgência. 
Além disso, recomenda-se respeitar a aparência das cidades e seu caráter, principalmente nas proximidades dos monumentos. Isto é, aderir plantações cuja caracterização valorize a conservação dos monumentos e edifícios, retirar outdoors, fios elétricos, tudo que não contribua ao "embelezamento" das obras, usar materiais modernos, mas sem o intuito de alterar os aspectos dos prédios restaurados. Quanto às ameaças surtidas pelos agentes atmosféricos, é demandada a colaboração dos responsáveis de cada Estado signatário por meio de estudiosos das áreas de química, física, ciências naturais e arquitetos. Caso esculturas não resistam aos agentes, recomenda-se a substituição por moldes das mesmas no referido local e, antes de toda, consolidação ou restauração, deverá ser feita a análise detalhada de elementos que podem concernir o processo.

Já a Carta de Atenas, em 1933, um manifesto do Conselho Internacional de Arquitetura Moderna (CIAM), teve o seguinte objetivo: solucionar os problemas da arquitetura contemporânea gerados pelo crescimento das novas cidades e apresentar planos da arquitetura moderna, fazendo com que a ideia adentrasse os meios técnicos, sociais e econômicos. Ademais, trouxe para discussão os aspectos de, por exemplo, a necessidade de um planejamento infraurbano e regional, verticalização dos edifícios presentes em áreas verdes, isto é, uma visão conhecida como "urbanismo racionalista".

Se compararmos as duas cartas de Atenas, perceberemos que a diferença está em seus objetivos: a primeira documenta as orientações adotadas quanto às restaurações de monumentos, a segunda traz os novos rumos que poderão ser traçados pela urbanização em tempos modernos. Desta forma, percebe-se ainda uma proteção parca se comparadas com os parâmetros de relevância histórica e cultura, posto que as cartas tinham o objetivo de garantir a proteção sobretudo visando a urbanidade e o embelezamento das cidades, fatores estes que, apesar de serem parte constitutiva do patrimônio, são insuficientes se considerarmos que a relevância do patrimônio enquanto garantia constitucional.

\subsection{Carta de Cartagena de Índias}

Entre tantos outros documentos para discussão, destaca-se a Carta de Cartagena de Índias, Colômbia, de 1999, elaborada pelo Conselho Andino de Ministros das Relações Exteriores da Comunidade Andina. Com seus nove artigos, traz consigo as seguintes considerações: 
Levando em conta as disposições da Convenção da UNESCO de 1970 sobre as medidas que se devem adotar para proibir e impedir a importação, exportação e transferência ilícita de propriedade de bens culturais; o Convênio de UNDROIT sobre os bens culturais roubados ou exportados ilicitamente, de 1995; e a Convenção de São Salvador sobre a defesa de patrimônio arqueológico, histórico e artístico das nações americanas, de 1976.

Seu objetivo principal está transcrito em seu Artigo $1^{\circ}$ :

Artigo 1. A presente decisão tem por objetivo promover políticas e normas comuns para a identificação, registro, proteção, conservação, vigilância e restituição dos bens que integram o patrimônio cultural dos países da Comunidade Andina e também para conceber e pôr em prática ações que impeçam sua importação, exportação e transferência ilícita entre os paísesmembros e a terceiros.

Para atingir sua finalidade, os países membros se comprometem em estabelecer serviços adequados de proteção - criação de leis, projetos educativos para desenvolver respeito às diferentes sociedades, organização de listagens de bens patrimoniais - além de transmitir informações sobre registros, identificação e a restituição às autoridades policiais, de portos e fronteiras, caso necessário.

Ao serem devolvidos, os bens culturais ou documentais deverão ser oficializados de forma diplomática, para fins de registro à Secretaria da Comunidade Andina. Os paísesmembros da dita comunidade são: Colômbia, Equador, Peru e Bolívia. O Chile não mais integrava o bloco econômico pela sua saída em 1976, na época da ditadura de Augusto Pinochet.

Aqui já se tem um avanço se comparado às Cartas de Atenas, posto que fica expressamente salvaguardada as diferentes expressões culturais. Por serem países demasiadamente heterogêneos, essa é uma especificidade essencial para o contexto latinoamericano, posto que, para ser perpetuada a histórica cultural de um povo, devem ser abarcadas as diferentes expressões cultuais enquanto manifestação da identidade deste povo.

\subsection{Carta de Mar Del Plata}

Anteriormente, outro bloco econômico que firmou uma carta patrimonial foi o Mercosul, no ano de 1997, desta vez acerca do patrimônio cultural intangível, o imaterial. Como exemplos do intangível que forma um patrimônio cultural, temos as festividades, celebrações, danças populares, músicas, folclores e costumes. A preocupação da UNESCO

Rev. Iberoam. Patrim. Histórico-Educativo, Campinas (SP), v. 6, p. 1-28, e020027, 2020. 
quanto ao tratamento e salvaguarda do patrimônio intangível - que é materializado nas manifestações dos povos - foi integrada na documentação, junto ao entendimento da existência de projetos e atividades em universidades, organismos de pesquisa e fundações cujas contribuições são promovidas em prol do estudo de assuntos com grande importância.

A Carta de Mar Del Plata é dividida em princípios e recomendações, iniciando com as declarações de que "A integração cultural deve ser definida como genuína prioridade do Mercosul e não meta marginal, para a qual irá requerer meios adequados a seus objetivos, assim como o indispensável respaldo político dos governos" e esta "Dita integração deve aceitar a pluralidade de culturas da região como fato positivo e enriquecedor da nossa visão de mundo e do próprio desenvolvimento da personalidade humana".

Outrossim, verifica-se que o legado das regiões são constituídos por culturas distintas: pré-colombianas, europeias, africanas e asiáticas, estas cujas mestiçagens deram vida às fisionomias singulares e que devem ser assumidas como fator de fortalecer o "patrimônio comum".

Nas recomendações, solicitam a viabilização de registro documental, catalogação e a criação de um corpo de dados das expressões usadas por cada comunidade, o incentivo de pesquisa de fontes das tradições regionais comuns - inclusive indígenas - e o estímulo do governo para possibilitar currículos educativos e ampliar o turismo com base na herança deixada na cultura, uma maneira inteligente de ampliar o desenvolvimento social.

A partir desta análise, percebe-se a importância que a preservação do patrimônio adquiriu no cenário jurídico dos países do Mercosul, posto que passa a ser prioridade e não apenas mera garantia capilarizada. Ademais, percebe-se o reconhecimento do sincretismo cultural das nações colonizadas, considerações estas essenciais quando se pretende salvaguardar a cultura nativa e indígena, o que permite indicar os acertos deste dispositivo jurídico regional, posto que o olhar dos países colonizados promove a devida vivência e separação das culturas europeias e as latino-americanas.

\subsection{Recomendações de Paris}

Por fim, temos as Recomendações de Paris, realizadas nos anos de 1972, 1989 e 2003, realizadas e aprovadas pela Conferência Geral da Organização das Nações Unidas para a Educação, a Ciência e a Cultura (UNESCO), com os temas: proteção do patrimônio mundial, cultural e natural; a salvaguarda da cultura tradicional e popular; destruição 
internacional do patrimônio cultural e sobre a preservação do patrimônio digital, respectivamente. A cada nova recomendação criada, além da predominância da temática anteriormente criada, havia a sua atualização de acordo com o crescimento da sua relevância e seus principais objetivos, mostrando de que maneira eram importantes aos grupos sociais de cada Estado-membro da época.

Em 1972, o Ato Constitutivo da Organização previu que a UNESCO apoiaria a conservação, o avanço e a promoção do saber voltadas para a conservação e a proteção do patrimônio universal e recomendaria, aos interessados, as convenções internacionais estabelecidas com esta finalidade. Convenções, recomendações e resoluções internacionais dedicadas à proteção dos bens culturais e naturais foram levadas em consideração mostrando a importância que constitui, para os povos do mundo, a salvaguarda dos bens insubstituíveis, independentemente do povo ao qual pertençam. De fato, foi indispensável a adoção de novas disposições convencionais, a fim de constituir um sistema eficaz de proteção coletiva do patrimônio de valor universal excepcional e permanente.

Para auxílio, a declaração expôs a definição de "patrimônio cultural e natural" nos seus primeiros artigos:

ARTIGO 1. Para os fins da presente Convenção são considerados "patrimônio cultural":

- os monumentos: obras arquitetônicas, esculturas ou pinturas monumentais, objetos ou estruturas arqueológicas, inscrições, grutas e conjuntos de valor universal excepcional do ponto de vista da história, da arte ou da ciência,

- os conjuntos: grupos de construções isoladas ou reunidas, que, por sua arquitetura, unidade ou integração à paisagem, têm um valor universal excepcional do ponto de vista da história, da arte ou da ciência,

- os sítios: obras do homem ou obras conjugadas do homem e da natureza assim como áreas, incluindo os sítios arqueológicos, de valor universal excepcional do ponto de vista histórico, estético, etnológico ou antropológico.

ARTIGO 2. Para os fins da presente Convenção são considerados "patrimônio natural":

- os monumentos naturais constituídos por formações físicas e biológicas ou por conjuntos de formações de valor universal excepcional do ponto de vista estético ou científico;

- as formações geológicas e fisiográficas e as zonas estritamente delimitadas que constituam habitat de espécies animais e vegetais ameaçadas de valor universal excepcional do ponto de vista estético ou científico,

- os sítios naturais ou as áreas naturais estritamente delimitadas detentoras de valor universal excepcional do ponto de vista da ciência, da conservação ou da beleza natural.

ARTIGO 3. Cabe a cada Estado-parte da presente Convenção identificar e delimitar os diversos bens situados em seu território e mencionados nos $\operatorname{artigos} 1 \mathrm{e} 2$. 
Respeitando plenamente a soberania dos Estados, em cujo território se situa o patrimônio cultural e natural a que se referem os artigos 1 e 2 deste instrumento, e sem prejuízo dos direitos reais previstos pela legislação nacional sobre o mesmo, os Estados-parte da presente Convenção reconheceram aquilo que constituía patrimônio universal, com a proteção do qual a comunidade internacional tem o dever de cooperar. Ademais, nota-se o esforço por todos os meios apropriados, especialmente por intermédio dos programas de educação e de informação, em reforçar o respeito e o apreço de seu povo pelo legado cultural e natural deixado a eles.

Na recomendação de 1989, com a definição do que é cultura tradicional e popular ${ }^{6}$, considerando esta que é um poderoso meio de aproximação entre os diferentes povos e grupos (nacionais, profissionais, religiosos, étnicos, sociais), a Conferência Geral recomenda aos membros a aplicação de disposições relativas à salvaguarda da cultura tradicional e popular, através da adoção de medidas legislativas ou de outra índole que sejam consideradas necessárias, em conformidade com as práticas constitucionais de cada Estado, com vista a que os princípios e medidas definidos na presente recomendação produzam efeitos nos seus territórios.

Para o efeito, os Estados deveriam fomentar, em nível nacional, regional e internacional, pesquisas adequadas com vista a estabelecer um inventário nacional das instituições que se ocupam da cultura tradicional e popular, para fins da sua inclusão nos registros regionais e mundiais de instituições desta ordem; para promover uma divulgação adequada da diversidade de culturas e de visões de mundo (em particular, as que não fazem parte da cultura dominante), deveriam os signatários incentivar eventos como feiras, festivais, exposições, congressos apoiando a divulgação e publicação dos respectivos materiais, divulgação por parte da imprensa, dos editores, da televisão, da rádio e de outros meios de comunicação.

Por fim, recomenda-se, à cooperação internacional nos domínios da divulgação e da proteção da cultura tradicional e popular, o intercâmbio de todo o gênero de informações e de publicações científicas e técnicas, como a formação de especialistas, a concessão de subsídios

\footnotetext{
${ }^{6}$ A cultura tradicional e popular é o conjunto de criações que emanam de uma comunidade cultural fundadas na tradição, expressas por um grupo ou por indivíduos e que reconhecidamente respondem a expectativas da comunidade enquanto expressão de sua identidade cultural e social; as normas e os valores se transmitem oralmente, por imitação ou de outras maneiras. Suas formas compreendem, entre outras, a língua, a literatura, a música, a dança, os jogos, a mitologia, os rituais, os costumes, o artesanato, a arquitetura e outras artes.
} 
de viagem e de envio de pessoal e de equipamento científico e técnico, a promoção de projetos bilaterais ou multilaterais no domínio da documentação relativa à cultura tradicional e popular contemporânea, assim como cooperar estreitamente com vista a assegurar, internacionalmente, o gozo dos direitos pecuniários, decorrente de criações, composições, gravações e/ou difusões da cultura tradicional e popular, por parte dos seus diversos titulares (comunidades ou pessoas físicas e jurídicas).

Em 2003, enfim, a 32a sessão da UNESCO contemplou a matéria de direitos humanos, particularmente os aspectos tratados na Declaração Universal de Direitos Humanos de 1948, no Pacto Internacional dos Direitos Econômicos, Sociais e Culturais e no Pacto Internacional dos Direitos Civis e Políticos, ambos de 1966. É mencionado o processo de globalização e, em meio à transformação social, em especial, como é possível gerar condições de diálogos entre as diferentes comunidades. Desta vez, reconhecem as comunidades indígenas como contribuintes que enriquecem a diversidade e criatividade humana. Sumariamente, tal convenção abre os olhos para a preservação da cultura imaterial, visando o respeito aos bens, à conscientização e ao reconhecimento.

A convenção reitera que nada disposto no documento pode ser interpretado como alteração ou diminuição ao estatuído no âmbito da Convenção para a Proteção do Património Mundial, Cultural e Natural, de 1972. A inovação foi a presença de órgãos auxiliares da convenção: a Assembleia Geral dos Estados-parte e o Comitê Intergovernamental para a Salvaguarda do Patrimônio Cultural Imaterial.

Mencionada anteriormente, a salvaguarda é dividida na sua visibilidade em escala nacional e internacional. Sem prejudicar a legislação nacional nos seus direitos e práticas consuetudinários, os Estados participantes reconhecem que a salvaguarda do patrimônio cultural imaterial é uma questão de interesse geral para a humanidade e comprometem-se, para esse fim, a cooperar em nível bilateral, sub-regional, regional e internacional. Com a intenção de assegurar uma melhor visibilidade do patrimônio cultural imaterial, fomentar a consciência da sua importância e favorecer o diálogo no respeito da diversidade cultural, o Comitê, mediante proposta dos Estados interessados, elabora, atualiza e publica uma Lista Representativa do Patrimônio Cultural Imaterial da Humanidade.

Com base em propostas apresentadas pelos Estados-parte e, de acordo com os critérios por si definidos e aprovados pela Assembleia Geral, o Comitê seleciona periodicamente e promove programas e atividades de caráter nacional, sub-regional ou regional de salvaguarda do patrimônio que julgue melhor refletirem os princípios da 
Convenção, tendo em conta as necessidades próprias dos países em vias de desenvolvimento. Promovendo a integração, a cooperação internacional inclui o intercâmbio de informações e experiências, iniciativas comuns, bem como a criação de um mecanismo de auxílio aos Estados signatários nos seus esforços para amparar o bem cultural imaterial.

O Comitê estabelece o procedimento para a análise dos pedidos de auxílio internacional e precisa os elementos do pedido, tais como as intervenções necessárias e a avaliação do custo dos mesmos. Como regra geral, o Estado-parte beneficiário deve participar, de acordo com os seus recursos, nos custos das medidas de preservação para as quais é prestado um auxílio internacional. O Estado-parte beneficiário apresenta ao conselho intergovernamental um relatório sobre a utilização do auxílio concedido a favor da defesa do patrimônio. A fim de que os representantes possam prever as suas operações de forma eficaz, as contribuições dos Estados devem ser pagas de forma regular, pelo menos de dois em dois anos, sob a pena de denúncia.

A Convenção está igualmente aberta à adesão dos territórios que gozem de uma total autonomia interna, reconhecida como tal pela Organização das Nações Unidas e que tenham competência nas matérias regidas pela Convenção, incluindo a competência reconhecida para celebrar tratados sobre tais matérias.

Desta forma, percebe-se que a manifestação das diversas culturas materializadas por meio do patrimônio é uma riqueza pertencente a todos os povos, o que desperta na comunidade internacional, por meio da UNESCO, a necessidade de normatizar a proteção ao patrimônio cultural, sem, contudo, ultrapassar a soberania dos estados signatários.

Estes mecanismos de proteção permitem a análise acerca da visão europeizada do patrimônio histórico e cultural, que partiu da proteção por meio pedagógico, passando pelo reconhecimento da cultura imaterial e finalizando-se com a instituição enquanto direito humano, contemplando, também, as expressões dos povos nativos. Por se tratarem de nações culturalmente mais homogêneas que as da América Latina, percebe-se, ainda assim, a insuficiência desse mecanismo enquanto protetor do patrimônio histórico, posto que apenas em 2003 reconheceu a diversidade dos povos, fatos estes abarcados anteriormente pelos dispositivos latino-americanos.

\section{Internalização das normas internacionais de proteção ao patrimônio histórico e cultural no Brasil}


Observando as medidas tomadas pelas cartas patrimoniais e acordos citados anteriormente, podemos trazer o assunto para o território brasileiro. Os registros começam na década de 1930, com a criação do Serviço de Patrimônio Histórico e Artístico Nacional (SPHAN), o qual trouxe em seu anteprojeto uma "teoria da preservação", contribuição este de nomes como Mário de Andrade e cujo principal objetivo seria a conservação museológica de bens e a inscrição de outros determinados bens para fins de tombamento (RUBINO, 1991). A criação deste órgão serve como o primeiro exemplo de internalização dos institutos internacionais de proteção ao patrimônio e histórico e cultural, sendo este também responsável pela divulgação do potencial turístico do ambiente urbano (AGUIAR e CHUVA, 2014).

Já na década de 1980 surgiu no interior do SPHAN a conduta de resgatar o patrimônio nacional a partir da perspectiva de Mário de Andrade (CHIVA, 2012). A fim de contemplar melhor a história nacional, foi-se agregando a essa ideia a necessidade de historicizar o processo de afastamento das políticas públicas do Estado. A concretização disso se deu com a edição do Decreto 3.551, de 4 de agosto de 2000, o qual regulamenta o tombamento, estudado mais à frente.

Adiante, segundo fontes do Instituto do Patrimônio Histórico e Artístico Nacional (IPHAN), o Brasil é signatário da convenção do patrimônio mundial, a Recomendação de Paris, desde o ano de 1977. O instituto exprime que a Convenção determina as classes de sítios naturais ou culturais considerados para inscrição na Lista do Patrimônio Mundial e fixa o compromisso que compete aos estados-membros quanto à identificação dos mesmos, além da proteção e preservação. Ao assinar a Convenção, cada país se compromete a conservar os bens do patrimônio mundial localizados no território como também o próprio patrimônio nacional.

Não obstante, o país não é subscritor apenas de cartas patrimoniais firmadas em territórios internacionais. Antes mesmo de fazer parte da Recomendação de Paris, criou documentos nacionais, tendo como exemplo o Compromisso de Brasília, de 1970 e uma temática que englobam nas suas discussões, ao mencionar as possibilidades de reformas e preservação é o "tombamento", cuja definição será apresentada posteriormente. Outro documento válido para menção é a Carta de Fortaleza, de 1997, ambos promovidos e oficializados na presença de personalidades celebres, desde líderes governamentais e de instituições até pessoas de áreas especializadas no patrimônio, bem histórico e cultural, material e imaterial. 


\subsection{Compromisso de Brasília}

Em abril de 1970, ocorreu o primeiro encontro de governadores de estado, secretários estaduais da área cultural, prefeitos de municípios interessados, presidentes e representantes de instituições culturais, evento promovido pelo Ministério da Educação e da Cultura para resolver o estudo da complementação das medidas à defesa do patrimônio histórico e cultural. Os dispositivos gerais mostram a compreensão dos estados e municípios o dever improrrogável o cuidado dos seus patrimônios históricos, de modo que deveriam ser tratados como preciosidades deixadas pelos antigos povos que habitaram o território anteriormente. Pensaram não somente nos edifícios, mas projetaram planos para a proteção da natureza.

Com o objetivo de manter a meta de proteção, recomendaram a criação de órgãos estaduais e municipais adequados, com a ajuda dos Conselhos Estaduais de Cultura e a Diretoria do Patrimônio Histórico e Artístico Nacional (DPHAN) para fins de unificações legislativas. Para remediar a carência de mão-de-obra especializada, decidiram ser imprescindível a criação de cursos visando a formação de arquitetos restauradores, conservadores de artes e documentos, arquivistas e museólogos de diferentes especialidades, orientados pela DPHAN. Ademais, concluíram que matérias com fundo de proteção hão de ser incluídas em escolas e universidades, servindo noções que estimulem a atenção para os monumentos representativos da tradição nacional e o incentivo da pesquisa.

Recomendava-se a defesa do acervo arquivístico, de modo a ser evitada a destruição de documentos, ou a preservação convenientemente, para cujo efeito será apreciável a colaboração do Arquivo Nacional. Às Secretarias competentes dos Estados, a promoção e divulgação do acervo dos bens culturais da respectiva área, utilizando-se os meios de comunicação de massas, tais como a imprensa, o cinema, a televisão. Havia, outrossim, necessidade premente do entrosamento com a hierarquia eclesiástica e superiores de Ordens religiosas e confrarias, para que todas as obras que venham a efetuar em imóveis de valor histórico ou artístico de sua posse, guarda ou serventia, sejam precedidas da audiência dos órgãos responsáveis pela proteção dos monumentos, nas regiões do País.

Finalmente, os participantes do encontro ouviram com muito agrado a manifestação do Ministro de Estado sensível à conveniência da criação do Ministério da Cultura, e 
consideram chegada esta oportunidade, tendo em vista a crescente complexidade e o vulto das atividades culturais do país.

Por se tratar de um documento da década de 1970, percebe-se, ainda, a falta de dispositivos que promovam a proteção não apenas do patrimônio histórico e cultural, mas também da sua diversa forma de expressão, sobretudo quanto à expressão cultural dos povos indígenas e nativos. Ressalte-se que, à época, o cenário político do país era o de um regime autoritário e ditatorial, tendo sido noticiado durante décadas o descaso com os povos nativos.

\subsection{Carta de Fortaleza}

Em 1997, em comemoração aos 60 anos de criação do Instituto do Patrimônio Histórico e Artístico, foi promovido o Seminário "Patrimônio Imaterial: Estratégias e Formas de Proteção" cujo objetivo era custear a elaboração de diretrizes e criação de instrumentos para proteger o patrimônio cultural de natureza imaterial brasileiro. $\mathrm{O}$ plenário do seminário levou em consideração a necessidade instituída pelos meios sociais e públicos na preservação do diversificado patrimônio cultural do país, cabendo ao IPHAN as medidas necessárias ao resguardo do patrimônio cultural, constituído de bens materiais e imateriais e estes com proteção específicas, considerando também que a proteção legal no âmbito federal, não se mostra adequada quando se refere ao patrimônio de bens imateriais.

A Carta de Fortaleza propõe e recomenda que se aprofunde o conceito de bem cultural de natureza imaterial, que sejam inventariados com a colaboração dos diversos segmentos públicos e de pesquisas e outros, que o resultado dos inventários seja integrado ao Sistema Nacional de Informações Culturais. Além de tudo, trouxe ao IPHAN total apoio, rejeitando qualquer medida que pudesse diminuir seu esforço para catalogar e realizar o reconhecimento dos bens patrimoniais do território, incentivando-o nas áreas de seu trabalho e a garantia da sua sobrevivência. Ademais, suplicam pela manutenção dos benefícios previstos na lei de Incentivo à Cultura e a enfim condecoração da cultura indígena como integrante do patrimônio brasileiro, devendo ser prestigiada pelo Ministério da Cultura.

Aqui conclui-se que se trata de uma norma mais abrangente e mais garantidora, posto que, o que faltava no Compromisso de Brasília agora já é observado na Carta de Fortaleza, a qual trouxe a necessidade da inclusão do patrimônio imaterial e da diversidade de expressão cultural dos povos indígenas enquanto objeto de proteção jurídica sendo esta a direção adequada para que se alcance a real proteção da expressão cultural material e imaterial.

Rev. Iberoam. Patrim. Histórico-Educativo, Campinas (SP), v. 6, p. 1-28, e020027, 2020. 


\subsection{Breves considerações acerca do "tombamento"}

Ao fim do Compromisso de Brasília, há um anexo assinado por Lucio Costa, retratando as problemáticas durante a recuperação de monumentos pela falta de técnicos e pessoas qualificadas para o trabalho, recursos financeiros e tombamento. No Direito Administrativo, "tombamento" é um dos elementos mais expressivos da proteção do patrimônio material (MARCHESAN, 2006) e constituiu um ato realizado pelo poder público federal, estadual e municipal a fim de preservar bens imóveis e móveis, tudo aquilo que possa possuir importância étnica, ambiental, cultural, histórica para a sociedade. A inclusão de um bem na lista de patrimônio mundial não significa que houve tombamento, mas apenas que o mesmo tem seu valor excepcional reconhecido nos termos da Recomendação de Paris, unicamente uma classificação.

No âmbito federal, temos a atuação do IPHAN como órgão preparado para a realização, seguindo a legislação predominante, sendo possível qualquer pessoa, física ou jurídica, pedi-lo. A demanda começa com o pedido de abertura por qualquer cidadão ou instituição e, após uma avaliação preliminar, é submetido a uma deliberação de organizações responsáveis pela preservação. Caso possua os requisitos, será enviada uma notificação ao proprietário para que fique ciente. A preservação é visível quando tal bem está na sua integral utilização e, ao mesmo tempo, proporcionando o reconhecimento da história vivenciada por povos de regiões que formaram nossa sociedade atual e nossa identidade.

Porém o tombamento não é o único método existente de preservação: o inventário, por meio do registro das principais características para o reconhecimento dos bens ambientais e culturais; e os planos diretores, promovidos pelos municípios por meio do planejamento urbano, além de legislações para providenciar a conservação. Por outro lado, isso não ocorre com o bem imaterial, pois não há perspectiva de impedir mudanças nessa forma de bem. Nossa linguagem, por exemplo, está em constante mudança com novas expressões e novos significados sendo empregados. O que pode ser feito é o seu registro, de modo a manter viva a sua referência cultural, exequível pela União, segundo o Decreto 3.551 de agosto de 2000.

\section{CONCLUSÃO}

A partir dessas reflexões, percebemos que "patrimônio" e "cultura" são concepções dificilmente desassociadas, e que demonstram não somente a expressão material, mas também 
os conhecimentos e identidades das diversas sociedades, transmitidas pela ancestralidade. Nesse compasso, vale ressaltar como o debate com a sociologia, antropologia, arquivologia e demais áreas das ciências sociais é essencial para a aplicação, com eficácia, das normas sobre preservação haja vista a necessidade de entender como cada sociedade tem vivências e expressões culturais específicas, sobretudo quando esses aspectos fazem parte da formação e identificação do indivíduo, em nível social, e da sociedade como um todo, a nível nacional.

Após o impacto das duas Grandes Guerras, a preocupação dos organismos internacionais com relação aos patrimônios ascendeu, conciliando, de início, a preocupação com a legislação dos países signatários e a conciliação dos interesses públicos e particulares e culminando na elaboração das mais diversas convenções e seus aspectos inovadores, como a proteção da esfera imaterial e de tudo aquilo que possa contribuir para a ordenação cultural, e a categorização e instituição do que seriam os "bens mundiais", na tentativa de fomentar investimentos e a cooperação internacional.

No cenário interno, o Instituto de Patrimônio Histórico e Artístico Nacional, como órgão da União, contribui para a autenticação do valor patrimonial de um bem histórico ou artístico, sua proteção, manutenção e salvaguarda, expressando essa proteção por meio do "tombamento" e do registro de bens imateriais também.

O que se percebe é que a preocupação internacional e interna para a proteção do patrimônio histórico e cultura não surge (e não deve surgir) meramente intentando a manutenção de bens que servem como atrativo turístico ou para embelezar o ambiente urbano, mas sim como uma necessidade compreendida a partir da reflexão acerca do papel da cultura dentro da sociedade, reflexão esta que só é possível por meio de um debate interdisciplinar.

Por fim, retomando-se os exemplos da discussão que deram início ao presente, percebe-se cada vez mais uma postura ativa da comunidade internacional em busca da proteção ativa do patrimônio histórico e cultural. Todos os mecanismos jurídicos aqui mencionados servem para nortear a atuação e os objetos de proteção, mas as ações têm sido percebidas por intermédio de órgãos constituintes das Nações Unidas, como foi o caso da intervenção do Conselho de Segurança nas cidades do Oriente Médio após os ataques do Estado Islâmico, ou até mesmo por meio de cooperação bilateral direta entre as nações, que foi o que ocorreu após o incêndio da Catedral de Nôtre Dame de Paris. 


\section{REFERÊNCIAS}

AÇÕES Internacionais e o Brasil. IPHAN. Disponível em:

http://portal.iphan.gov.br/pagina/detalhes/886\#: :text=O\%20Brasil\%20\%C3\%A9\%20signat \%C3\%A1rio\%20da,\%C3\%A1rea\%20de\%20preserva\%C3\%A7\%C3\%A3o\%20deste\%20patri m\%C3\%B4nio. Acesso em: 25 jun. 2020.

AGUIAR, Leila Bianchi e CHUVA, Márcia Regina Romeiro. Institucionalização das práticas de preservação do patrimônio cultural no Brasil e na Argentina e suas relações com as atividades turísticas. ANTÍTESES, Londrina/PR, v. 7, n. 14, p. 68-94, jul. - dez. 2014. Disponível em: file:///C:/Users/usuario/Downloads/18689-88626-1-PB.pdf. Acesso em 21 de dezembro de 2020.

ALENCAR, Lucas. 13 locais históricos destruídos pelo Estado Islâmico. Revista Galileu, 2016. Disponível em: https://revistagalileu.globo.com/Sociedade/noticia/2016/01/13-locaishistoricos-destruidos-pelo-estado-islamico.html. Acesso em: 9 jun. 2020.

BRASIL. Constituição (1988). Constituição da República Federativa do Brasil. Brasília, DF: Senado Federal. Disponível em:

http://www.planalto.gov.br/ccivil_03/constituicao/constituicao.htm. Acesso em: 10 jun. 2020.

BRASIL. Decreto-Lei ${ }^{\circ}$ 25, de 30 de novembro de 1937. Rio de Janeiro, DF. Disponível em: http://www.planalto.gov.br/ccivil_03/decreto-lei/del0025.htm. Acesso em 22 de dezembro de 2020.

CANEDO, Daniele Pereira. Cultura é o quê? - reflexões sobre o conceito de cultura e a atuação dos poderes públicos. In: V ENCONTRO DE ESTUDOS MULTIDISCIPLINARES EM CULTURA - ENECULT. Anais [...]. Salvador, 2009. Disponível em: http://www.cult.ufba.br/enecult2009/19353.pdf. Acesso em: 10 jun. 2020.

CARTA de Atenas. 1931. Disponível em: http://portal.iphan.gov.br/uploads/ckfinder/arquivos/Carta\%20de\%20Atenas\%201931.pdf. Acesso em: 17 jun. 2020.

CARTAS de Atenas. 1933. Disponível em: http://portal.iphan.gov.br/uploads/ckfinder/arquivos/Carta\%20de\%20Atenas\%201933.pdf. Acesso em: 17 jun. 2020.

CARTA de Cartagena de Índias, Colômbia. 1999. Disponível em: http://portal.iphan.gov.br/uploads/ckfinder/arquivos/Cartagenas\%20de $\% 201 \% \mathrm{CC} \% 81$ ndias $\%$ 20-\%20Colombia\%201999.pdf. Acesso em: 21 jun.2020.

CARTA de Fortaleza. Disponível em: http://portal.iphan.gov.br/uploads/ckfinder/arquivos/Carta\%20de\%20Fortaleza\%201997.pdf. Acesso em: 22 jun. 2020.

CARTA de Mar del Plata sobre Patrimônio Intangível. Disponível em: http://portal.iphan.gov.br/uploads/ckfinder/arquivos/Carta\%20de\%20Mar\%20del\%20Plata\%2 01997.pdf. Acesso em: 22 jun. 2020. 
CHUVA, Márcia. Por uma história da noção de patrimônio cultural no Brasil. Revista do Patrimônio Histórico e Artístico Nacional, Brasília/DF, n. 34, p. 147 - 165, 2012. Disponível em: http://portal.iphan.gov.br/uploads/ckfinder/arquivos/Numero\%2034.pdf. Acesso em 21 de dezembro de 2020.

COMPROMISSO de Brasília. 1970. Disponível em:

http://portal.iphan.gov.br/uploads/ckfinder/arquivos/Compromisso\%20de\%20Brasilia\%20197 0.pdf. Acesso em: 21 jun. 2020.

CONSELHO DE SEGURANÇA DA ONU (CS). Resolução 2347/2017. Disponível em: https://www.un.org/press/en/2017/sc12764.doc.htm. Acesso em: 9 jun. 2020.

DURANTI, A. Linguistic Anthropology. Cambridge: Cambridge University Press, 1997.422 p.

GODOY, Elenilton Vieira; SANTOS, Vinício de Macedo. Um olhar sobre a cultura.

Educação em Revista, Belo Horizonte/MG, v. 30, n. 03, p. 15-41, jul./set. 2014. Disponível em: https://www.scielo.br/pdf/edur/v30n3/v30n3a02.pdf. Acesso em: 9 jun. 2020.

LARAIA, Roque de Barros. Cultura: um conceito antropológico. 14. ed. Rio de Janeiro: Jorge Zahar, 2001. 117 p.

LEMOS JÚNIOR, Clésio Barbosa. Patrimônio cultural: conceitos, proteção e direito pela educação patrimonial. Revista do Curso de Direito do UNIFOR, Formiga/MG, v. 3, n. 2, p. 50-61, out. 2015. Disponível em: file:///C:/Users/usuario/Downloads/136-

Texto\%20do\%20artigo-427-1-10-20121025\%20(2).pdf. Acesso em: 10 jun. 2020.

LOPIS, Erivania Azevedo. Patrimônio histórico cultural: preservar ou transformar? Uma questão conflituosa. Revista Mosaico, Rio de Janeiro/RJ, v. 8, n. 12, p. 9-23, 2017.

Disponível em: file:///C:/Users/usuario/Downloads/65461-144791-1-PB.pdf. Acesso em: 9 jun. 2020.

MARCHESAN, Ana Maria Moreira. A tutela do patrimônio cultural sob o enfoque do direito ambiental: uma abordagem transdisciplinar. 2006. 327 p. Dissertação (Mestrado em Direito) - Universidade Federal de Santa Catarina, Florianópolis/SC, 2006.

MELO, Alessandro de; CARDOZO, Poliana Fabiula. Patrimônio, turismo cultural e educação patrimonial. Educ. Soc., Campinas/SP, v. 36, n. 133, p. 1059-1075, out./dez. 2015. Disponível em: https://www.scielo.br/pdf/es/v36n133/1678-4626-es-36-133-01059.pdf. Acesso em: 9 jun. 2020.

MOURA, Angela Acosta Giovanini de. A proteção internacional do patrimônio cultural. Cadernos de Direito, Piracicaba/SP, v. 12, n. 23, p. 91-110, jul./dez. 2012. Disponível em: file:///C:/Users/usuario/Downloads/1003-5636-1-PB.pdf. Acesso em: 10 jun. 2020.

ONU condena destruição de patrimônio cultural em Palmira pelo Estado Islâmico. Nações Unidas Brasil, 2017. Disponível em: https://nacoesunidas.org/onu-condena-destruicao-depatrimonio-cultural-em-palmira-pelo-estado-islamico/. Acesso em: 9 jun. 2020. 
PATRIMÔNIO Cultural do Mercosul. IPHAN. Disponível em:

http://portal.iphan.gov.br/pagina/detalhes/411. Acesso em: 10 jun. 2020.

PORTO, Cristiane de Magalhães. Um olhar sobre a definição de cultura e de cultura científica. In: PORTO, Cristiane de Magalhães; BROTAS, Antonio; BORTOLIERO, Simone (Orgs.). Diálogos entre ciência e divulgação científica: leituras contemporâneas. Salvador: EDUFBA, 2011, 240 p. Disponível em: http://books.scielo.org/id/y7fvr. Acesso em: 12 jun. 2020.

RECOMENDAÇÃO de Paris. 1972. Disponível em: http://portal.iphan.gov.br/uploads/ckfinder/arquivos/Recomendacao\%20de\%20Paris\%201972 .pdf. Acesso em: 15 jun. 2020.

RECOMENDAÇÃO de Paris. 1989. Disponível em: http://portal.iphan.gov.br/uploads/ckfinder/arquivos/Recomendacao\%20Paris\%201989.pdf. Acesso em: 15 jun. 2020.

RECOMENDAÇÃO de Paris. 2003. Disponível em: http://portal.iphan.gov.br/uploads/ckfinder/arquivos/Recomendacao\%20Paris\%202003.pdf. Acesso em: 15 jun. 2020.

RUBINO, Silvana. As fachadas da historia: os antecedentes, a criação e os trabalhos do Serviço do Patrimonio Historico e Artistico Nacional, 1937-1968. 1991. [209]f.

Dissertação (mestrado) - Universidade Estadual de Campinas, Instituto de Filosofia e Ciencias Humanas, Campinas, SP. Disponível em:

http://www.repositorio.unicamp.br/handle/REPOSIP/281677. Acesso em: 20 de dezembro de 2020.

SILVA, Frederico A. Barbosa da. Política cultura no Brasil, 2002-2006: acompanhamento e análise. Brasília/DF: Ministério da Cultura, 2007. 240 p. (Coleção Cadernos de Políticas Culturais, v. 2). Disponível em:

http://repositorio.ipea.gov.br/bitstream/11058/3245/1/cadvol2.pdf. Acesso em: 11 jun. 2020.

THOMPSON, John. B. Ideologia e cultura moderna: teoria social crítica na era dos meios de comunicação de massa. Petrópolis/RJ: Vozes, 2009. 427 p.

UNESCO lança iniciativas para apoiar cultura e patrimônio durante a pandemia. 2020. Disponível em: https://nacoesunidas.org/unesco-lanca-iniciativas-para-apoiar-cultura-epatrimonio-durante-a-pandemia/. Acesso em: 10 jun. 2020.

UNESCO. Convention Concerning the Protection of the World Cultural and Natural Heritage. 1972. Disponível em: https://unesdoc.unesco.org/ark:/48223/pf0000133369. Acesso em: 10 jun. 2020.

WEBER, Max. Ensaios de Sociologia. 5 ed. Rio de Janeiro/RJ: LTC, 1982. 530 p.

Recebido em: 31 de julho de 2020 Aceito em: 12 de novembro de 2020 
